\title{
Spatial Conservation of Ecological Landscape-Hydrologic Responses to Land Use Change in Datu Tableland
}

\author{
Ying-Ping Tien, Kuo-Chen Chang, Nae-Wen Kuo \\ Department of Geography, National Taiwan Normal University, Taipei, Taiwan \\ Email address: \\ noah0901@hotmail.com (Ying-Ping Tien), twnrsworld@hotmail.com (Kuo-Chen Chang), niven@ntnu.edu.tw (Nae-Wen Kuo) \\ To cite this article: \\ Ying-Ping Tien, Kuo-Chen Chang, Nae-Wen Kuo. Spatial Conservation of Ecological Landscape-Hydrologic Responses to Land Use \\ Change in Datu Tableland. Automation, Control and Intelligent Systems. Vol. 5, No. 6, 2017, pp. 96-107. doi: 10.11648/j.acis.20170506.13
}

Received: October 17, 2017; Accepted: November 16, 2017; Published: December 18, 2017

\begin{abstract}
Datu Tableland is located at the land of Taichung Basin and Taichung's Western Coastal Plain in central Taiwan. It is a large Urban Green Corridors with multi-functions of Ecological Service. It was suffered by flooding happened by humanmade activities such as the development of scientific industrial park in recent years. This research collects data from different government agencies, including remote sensed data, 2009 digital land use data, soil data to establish the model of analyzing the changes of Ecological Service. Through analyzing and interpreting these data this study produce the layer of vegetation coverage and water storage capacity. At the same time, this study use arcgis database to manage and analyze the files efficiently. Dividing Datu Tableland to three subwatersheds makes the distribution of the changing of land use meaningful. It indicates landscape effects hydrological index and ecological vegetation coverage actually. This paper also estimates potential maximum retention amount in three subwatersheds. The total water storage capacity are estimated along urbanization and industrial development. The process of quantifying the impacts of LULC changes on hydrology at different scales including geomorphological and hydrological scales provides quantitative information for making decisions for land and water resource management. This paper also links landscape ecological thinking and hydrological thinking to ecological service analysis. The anticipated benefits for flood reduction by water storage facilities may be also received.
\end{abstract}

Keywords: Vegetation Coverage, Water Interception and Storage, Flood Reduction

\section{Introduction}

Land cover changes induced by human activities has impacted environment and attracted increased research interest in recent decades [1] [6]. Human activities and natural succession have cumulative effect to landscapes and land cover changes usually come from the accumulation of small area's changes. It is easy to be ignored because the land cover changes are too slow. People pay attention to these changes finally until it is known to influence ecological communities, surface water hydrology and soil properties [7]. Such change influence surface water hydrology, underground water hydrology, and evaporation directly [8] [9] [10]. It also has different impacts in different spatial-time scale [11]. The process of land cover changes has the important power for ecosystem and ecological service function and it effects the construction, the functions and ecological diversities of ecosystem [12]. In landscape ecology Many papers discuss land cover changes influence the hydrologic response in places and basins usually are the research aim [13] [8] [14]. In recent years some papers also research land cover changes effect the ecological characteristics [15].

Above all, few people discuss these issues according to the view of geomorphology. The characteristics of a geomorphological unit are meaningful when researchers discuss the impacts of human-induced land cover changes. The slopes, aspects, the distribution of tectonic geology, and the properties of soil effect the process of hydraulic environment. Processes of hydraulic characteristics changes as land cover changes in a terrain unit. Few papers research how to establish an approach of monitoring the function of landscape ecological service and discuss the quantification project and conservation Inventory.

The increasing natural disasters, especially floods during the last quarter century, are raising the economic losses in Taiwan. Rapid urbanization without proper land uses managements usually worsen the flood problems. The most severe hazard in Taiwan is flooding induced by typhoons and 
storms in summer and autumn. By comparing the rivers around the world, the ones in Taiwan have the steepest slopes, the largest discharge per unit drainage area, and the shortest time of concentrations.

Datu Tableland is between the land of Taichung Basin and Taichung's Western Coastal Plain. It is a large Urban Green Corridors with multi-functions such as recreation, water resources conservation, air purification, and Ecological Service.

The land use change Of Datu Tableland along the development of Central Taiwan Science Park in 2000 to 2014 makes Datu Tableland flooding induced by typhoons of SAOLA, KONG-REY, SOULIK. The situation lets us to think two question: (1) Is the vegetation coverage degraded along the development? (2) Is the water storage capacity degraded along the development?

In this study, the remotely sensed data (Formosat2) for grassland before and after Tableland development are used to evaluate the vegetation coverage benefits by the established green index for land cover discrimination. The total water storage capacity are estimated before and after Tableland development by digital national land use data, and several environmental digital data for landscape.

\section{Materials and Methods}

\subsection{Study Area and Delineation of Sub-Watersheds}

The Dadu Plateau is also known as Dadu Mountain or
Dadushan, stretches across Taichung City in central-western Taiwan. It faces the Taichung Basin on the east and the seacoast of Taichung on the west, and lies between the Dajia River and Datu River. The plateau is long and narrow, has a length of about $20 \mathrm{~km}$, and a width of about 5 to $7 \mathrm{~km}$. It average height is about $151 \mathrm{~m}$, with a highest peak which has a height of $310 \mathrm{~m}$ [2]. It is known for its grounds covered in red clay, has rather limited options when it comes to cultivating agricultural produce (see Figure 1) [21]. The annual average temperature is about $21.6^{\circ} \mathrm{C}$, annual rainfall is about $1,452 \mathrm{~mm}$; there are humid seasons from May to September, and it is little rain form October to April. The climate is typical sub-tropical monsoon climate. This study delineate the research area to three sub-watersheds as seen in Figure 2: The first one is the sub-watershed of Datu river, represented as SW-1; the second is the sub-watershed of steep river in the west, represented as SW-2; the third is the sub-watershed of dajia river, represented as SW-3.

The types of land cover transformed from Formosat2 image in 2014 include: cropfarm (dry farmland, Paddyfield, Fruit tree) is $23.63 \%$; forest (coniferous forest, evergreen forest, mixed forest) is $10.80 \%$; grassland (Park and grave) is $5.60 \%$; open water is $1.14 \%$; artificial constructon is $44.35 \%$; wasteland is $14.47 \%$. Many scholars have researched that the red clay in Datu Tableland leads to sediment disaster on the slopeland easily. The excessive rainfall also would cause flood in the lowlands. The property and safety of resident are threatened by the disaster [2].

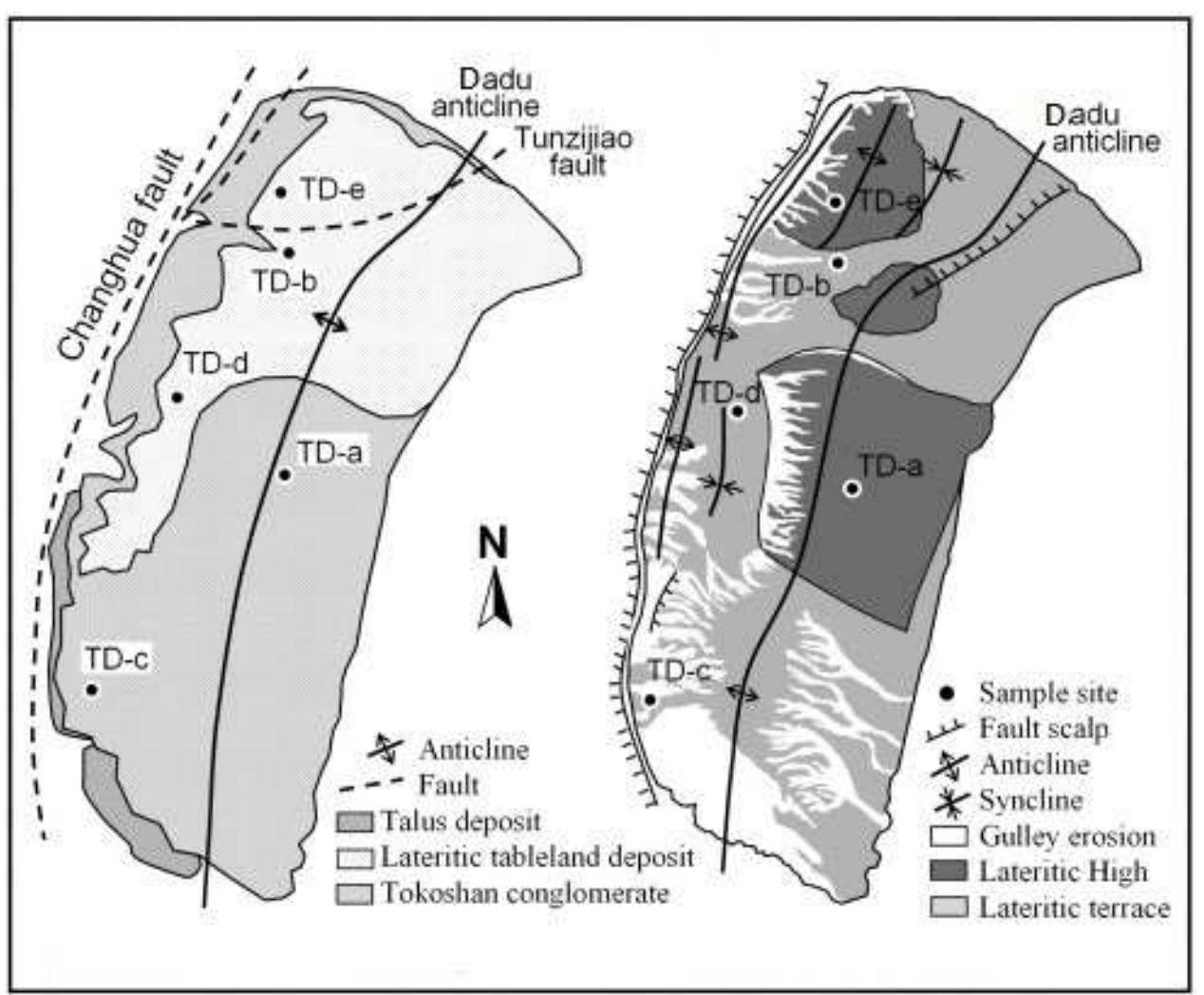

(Modified from Tsai, 2009)

Figure 1. Topography of Datu Tableland. 


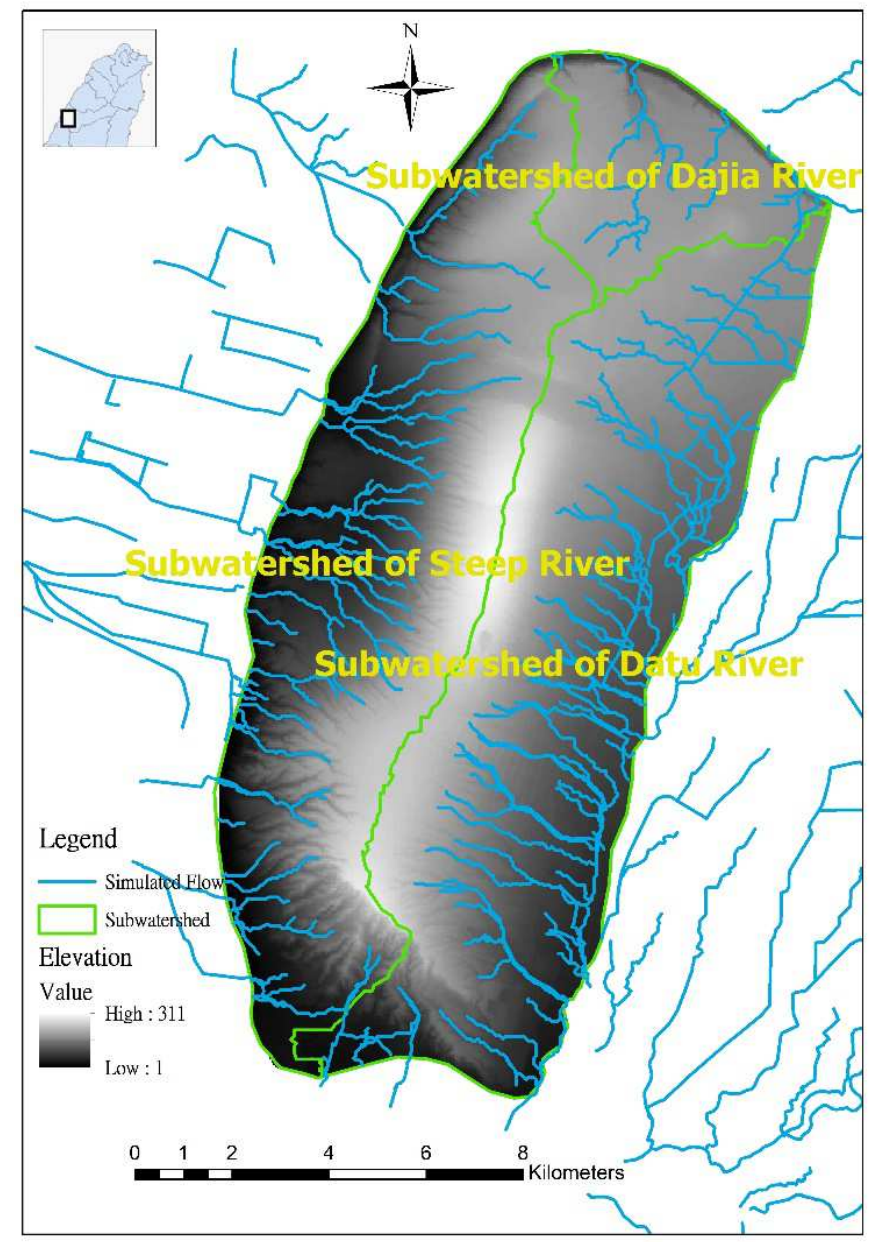

Figure 2. The study area of Datu Tableland.

\subsection{Materials and Methods}

The study's implementation required research techniques developed in a variety of fields. In addition to office work and field surveys, it involved the use of Geographic Information System (GIS), vegetation coverage transformed from Remote Sensing (RS), land change modelling and water storage capacity analysis. These techniques are used to identify landscapes, and indicate ecological index, land cover changes and their effects on the hydrological response. The following materials and software were also used in the study's implementation: the ESRI ArcGIS Spatial Analyst extension, ERDAS Imagine 2013 and satellite imagery. The main data collected were as follows (Table 1):

Table 1. study material.

\begin{tabular}{lllll}
\hline Map/Data & Resolution & Year & Source & Purpose \\
\hline Formosat2 MS & $2 \mathrm{~m} \times 2 \mathrm{~m}$ & 2008,2014 & NTNU & Environmental data extraction \\
Soil map & $1 / 5000$ & 2015 & TARI & Estimate CN \\
Land use & $1 / 5000$ & 2009 & NLSC & Estimate CN \\
DEM & $40 \mathrm{~m} \times 40 \mathrm{~m}$ & 1986 & ASO & Analysis of geomorgraphy Watershed extraction \\
\hline
\end{tabular}

Assessing the spatial changes in the water storage capacity between 2008 and 2014 and estimating the hydrological response to land cover changes and projections was carried out in several steps, as shown in the workflow chart in Figure 3. Field surveys were conducted between January and Feburary in 2014. Land cover mapping of 2008 and hydraulic analysis were performed by the survey of land-use produced by the National Land Surveying and Mapping Center (NLSC) from 2008 and 2009. Land-use data of 2015 were processed using Formosat 2 image based on the outline of land-use digital data. During the field surveys, visualization of the specific land cover (eg: dry farmland) was made to collect ground truth points for classification and observe the human effects on land cover changes. More than 1000 ground truth points were collected during the several field surveys. The land cover classification was based on these ground truth points using geocoded ground observation points and visual interpretations of Google Earth images. 


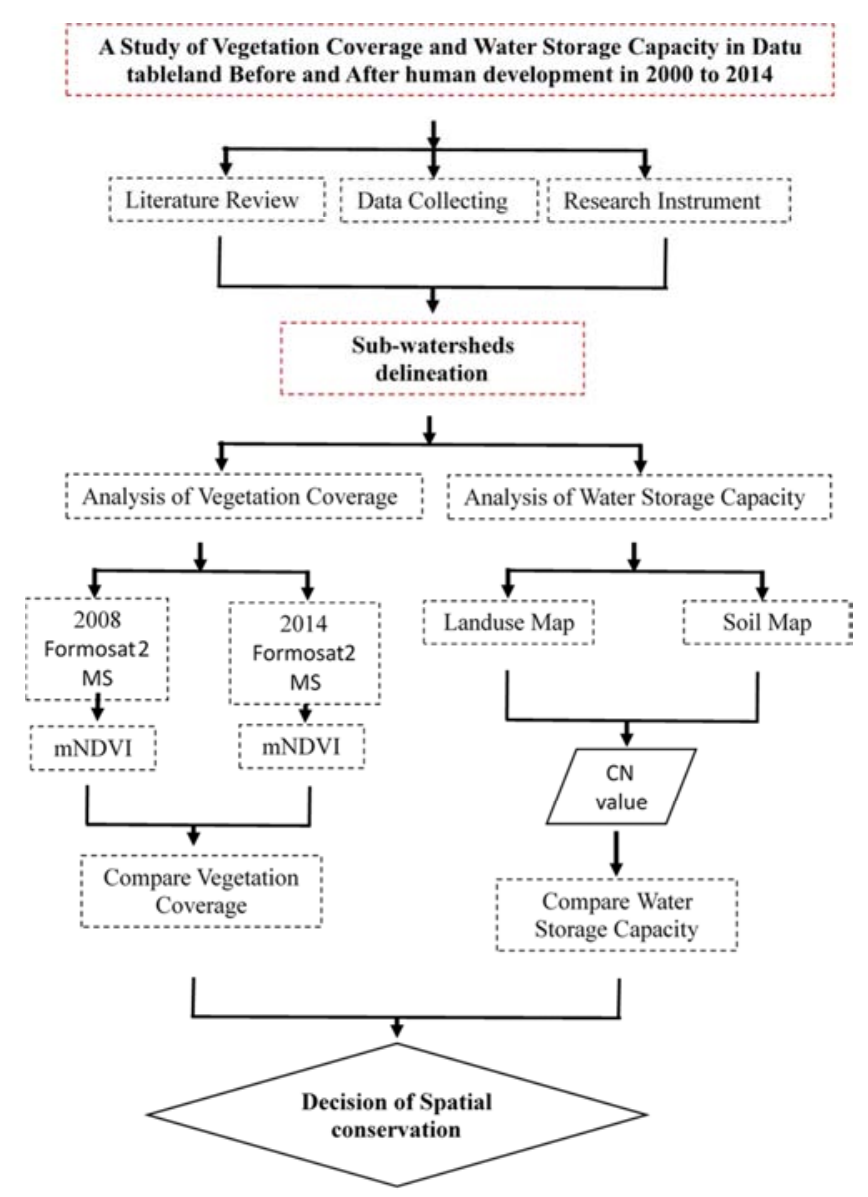

Figure 3. The study flowchart.

\subsection{Soil Texture Map}

The soil map for the study area developed by previous survey of Taiwan Agricultural Research Institute (TARI). Soil polygons were collected from the entire study area and then analysed in ArcGIS to develop a soil texture map for the study area. The map was divided into four classes as A, B, C, and D is considered using the SCS method. These classes correspond respectively to "high", "moderate", "slow", and "almost no" infiltration rates. The components of soil include loam, clay and silty clay and the study area revealed $85.8 \%$ areas are made up of red clay soil classified as Group D, which has a low infiltration rate when it is thoroughly saturated. Group D comprised clay loam, silty clay loam, sandy clay, silty clay and clay soils. These soils have the greatest runoff potential. Dadu Tableland has low low infiltration rate and it is more important for local people to conserve the water storage capacity and the vegetation coverage benefits.

\subsection{Land Cover Classification}

\subsubsection{Data Pre-processing}

Formosat2 MS reflectance cloud-free images for 2008 and 2014 were obtained from National Taiwan Normal University (NTNU) (Table 1). These images were geometrically corrected and projected to the TWD97. This image was also employed as reference data and a base map for the assessment of classification and accuracy.

\subsubsection{Data Processing}

After pre-processing, the Formosat2 images were then processed using ERDAS Imagine 2013 ArcGIS 9.3 softwares. In addition, this research used a 2008 land cover map and Google Earth historical images for verification of the satellite image-based land cover classification. During the field surveys, visualisation of the specific land cover was made to collect ground truth points for classification and observe the human effects on land cover changes. More than 1000 ground truth points were collected during the two field surveys. The land cover classification was based on these ground truth points using geocoded ground observation points and visual interpretations of Google Earth images. Land cover classification was performed using classes of the SCS method in ArcGIS 9.3 Spatial Analyst to define the signature files and fix the number of classes (Table 2). The resulting raster layer provided delineation of the land cover classes and the land cover in the maps was classified into ten main classes: artificial constructon, coniferous forest, open water, dry farmland, Park and grave, Wasteland, Evergreen forest, Paddyfield, Fruit tree and Mixed forest.

Table 2. Curve number of SCS.

\begin{tabular}{|c|c|c|c|c|}
\hline $\begin{array}{ll}\text { Land cover } & \text { SCS soil class } \\
\end{array}$ & $\mathbf{A}$ & B & $\mathbf{C}$ & D \\
\hline Artificial constructon & 74 & 84 & 90 & 92 \\
\hline Coniferous forest & 25 & 55 & 77 & 77 \\
\hline Open water & 94 & 93 & 95 & 96 \\
\hline Dry farmland & 62 & 71 & 78 & 81 \\
\hline Park, grave & 39 & 61 & 74 & 80 \\
\hline Wasteland & 77 & 86 & 91 & 94 \\
\hline Evergreen forest & 36 & 60 & 73 & 79 \\
\hline Paddyfield & 70 & 79 & 84 & 88 \\
\hline Fruit tree & 45 & 66 & 77 & 83 \\
\hline Mixed forest & 38 & 62 & 74 & 80 \\
\hline
\end{tabular}

\subsection{Digital Elevation Model}

A $40 \mathrm{~m}$ digital elevation model (DEM) obtained from the Aerial Survey Office (ASO) was used to generate the subwatershed map for Dadu Tableland region. DEM analysis was performed to outline research areas to maintain flow continuity to the catchment outlets. A slope degree map was then generated for the study area from Dadu Tableland region DEM.

\subsection{Modelling the Vegetation Coverage and the Water Storage Capacity}

\subsubsection{The Vegetation Coverage}

This research calculate the distribution of mNDVI to understand the spatial vegetation coverage structure of ecological service in order to research functions of ecological service in Datu Tableland.

The normalized difference vegetation index (NDVI) is a simple graphical indicator that can be used to analyze remote sensing measurements. The NDVI is derived from the red: near-infrared reflectance ratio $\mathrm{NDVI}=(\mathrm{NIR}+\mathrm{RED}) /(\mathrm{NIR}-$ 
RED), where NIR and RED are the amounts of near-infrared and red light, respectively, reflected by the vegetation and captured by the sensor of the satellite]. The formula is based on the fact that chlorophyll absorbs RED whereas the mesophyll leaf structure scatters NIR. NDVI values thus range from +1 to -1 , where negative values correspond to an absence of vegetation [4]. Once the feasibility to detect vegetation had been demonstrated, users tended to also use the NDVI to quantify the vegetation biomass and coverage [3] [16].

It also can be an ecological function index to assess the quality of an ecosystem and the larger the NDVI presents the higher the basic production. It can satisfy the development of ecosystem and the potential capacity of ecological habitat quality is better [3] [4] [16] [17]. Many papers discuss these subjects. USEPA use NDVI as an index to assess landscape in heathy watershed integrity. Pang also develop a process of analyzing landscapes in the watershed by the assessment of the ecological quality and habitat fragmentation on the Toucian river basin [17]. Above all, it can indicate the quality of a ecological habitat and the changes of the basic production by using NDVI as a analyst of local ecosystem function. This paper adapt mNDVI which is transformed by the modification of NDVI according to Normalized formula developed from Lin [18] to assess the vegetation coverage. The flowchart can be seen in Figure 4.

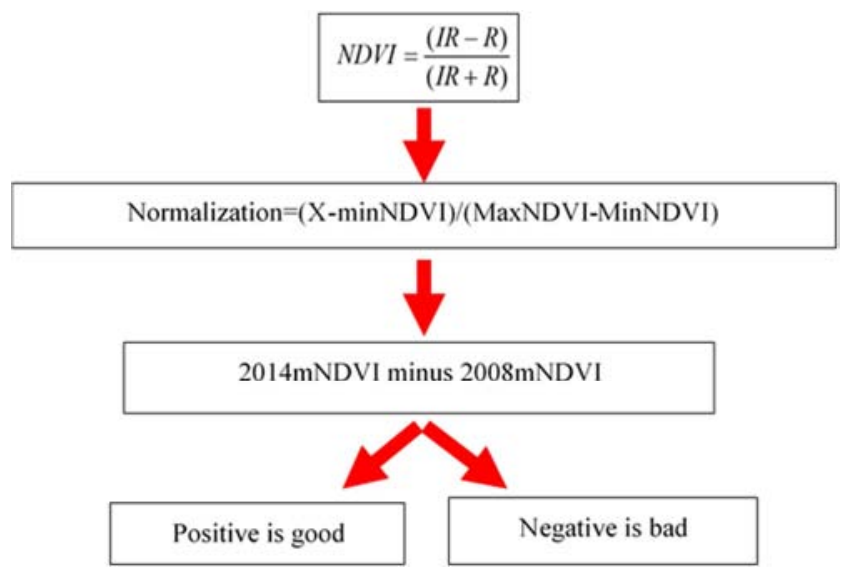

Figure 4. The flowchart of analyzing vegetation coverage.

\subsubsection{The Water Storage Capacity}

This research use the potential maximum retention amount as index of assessing water conservation, reducing soil erosion, and water purification.

SCS-CN method is used to investigate the watershed response to land cover changes because of its reliance on land cover parameters. The SCS-CN method has several advantages, chief amongst which is its ease of use and widespread acceptability, but it is also has several disadvantages. Nevertheless, its use is considered appropriate in the absence of accurate hydrological and topographical data for water storage capacity estimation [5].

The method's stability is ensured by the surface runoff depth (Q) being bounded between 0 and the maximum rainfall depth $(\mathrm{P})$, which implies that, as the amount of rainfall increases, the actual retention $(\mathrm{P}-\mathrm{Q})$ approaches a constant value, i. e. the maximum potential retention [6].

When the maximum potential retention becomes a constant value and scholars imply that there are different constant value in different land cover. it can be represented as curve number $(\mathrm{CN})$ as seeing in Table 2. If a land cover changes, it means the maximum potential retention (S) changes in the same place. If the amount of changes is smaller than the former there will be more surface runoff and the damages of flood will happen [18] [19].

This research can determine $\mathrm{CN}$ by the soil map and landuse/land cover map and calculate maximum potential retention (S) transformed by formula. the water storage capacity also effect the ability of water purification. a large number of water storage capacity can improve water quality and protect water resources to retain and infiltrate [20].

Chu compare the change of potential maximum retention between different development situations by evaluating the SCS curve number and potential maximum retention in Taichung Metropolitan Park and Central Taiwan Science Park in Dadu terrace [19]. The results show that the potential maximum retention in 2009 is lower than in 1995. This paper adapt this method to monitor the ecological function in Datu Tableland. The flowchart can be seen in Figure 5.

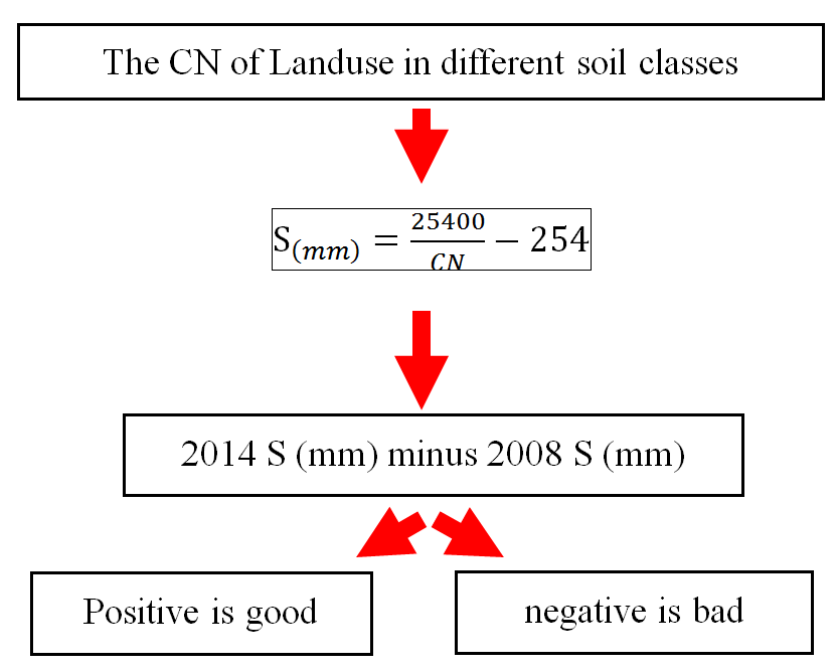

Figure 5. The flowchart of analyzing the water storage capacity.

\section{Results and Discussion}

\subsection{Analysis of the Vegetation Coverage}

This paper adapt mNDVI which is transformed by the modification of NDVI according to Normalized formula and assess the vegetation coverage in order to assess the ecological function. The distribution map of mNDVI for 2008 can be seen in Figure 6 (b). We also calculate and get the distribution map of mNDVI for 2014 (Figure 7 (b)). The information of the vegetation coverage in the research area and sub-watersheds can be seen in Table 3 . 

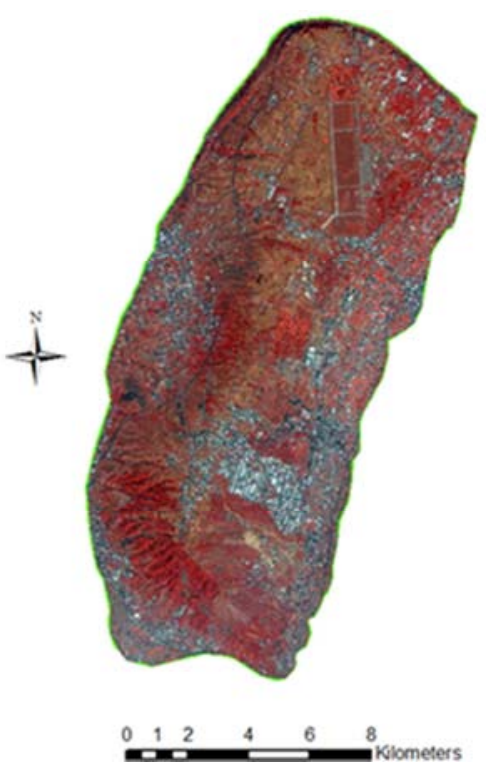

(a)

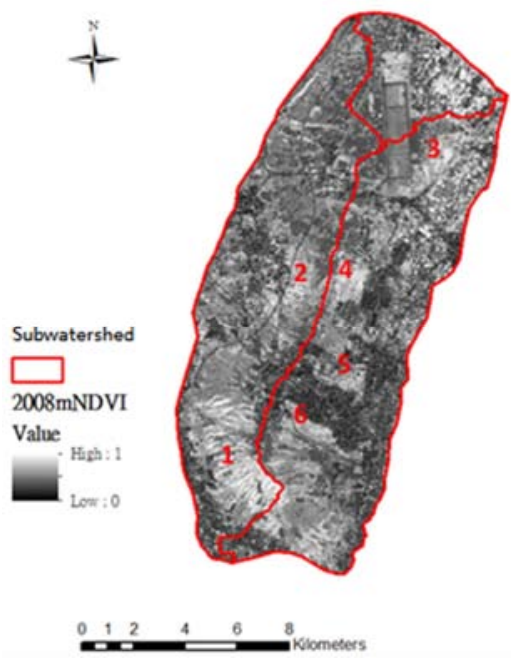

(b)

Figure 6. 2008 FS2 image (a) and The distribution map of mNDVI for 2008 (b)

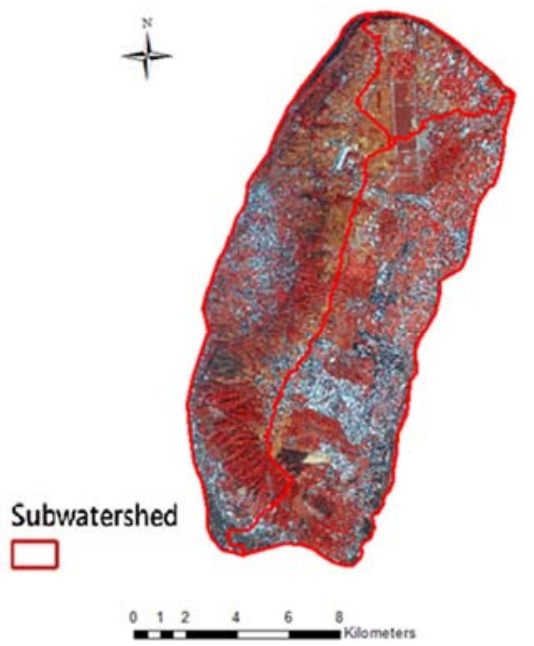

(a)
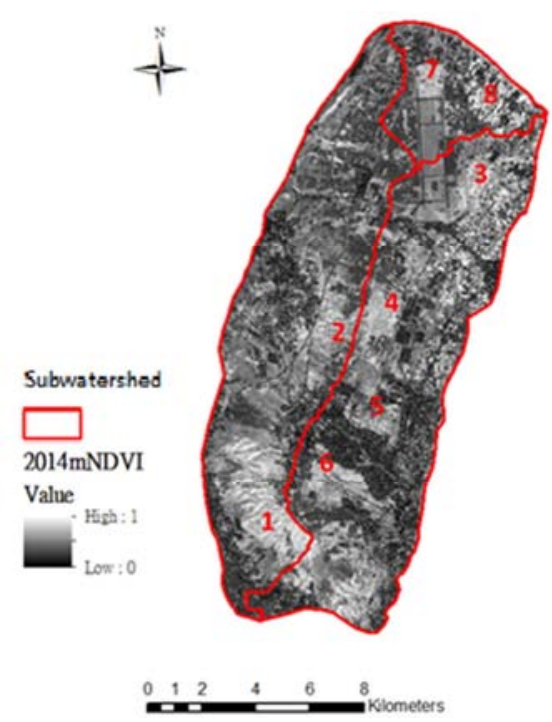

(b)

Figure 7. 2014 FS2 image (a) and The distribution map of mNDVI for 2014 (b).
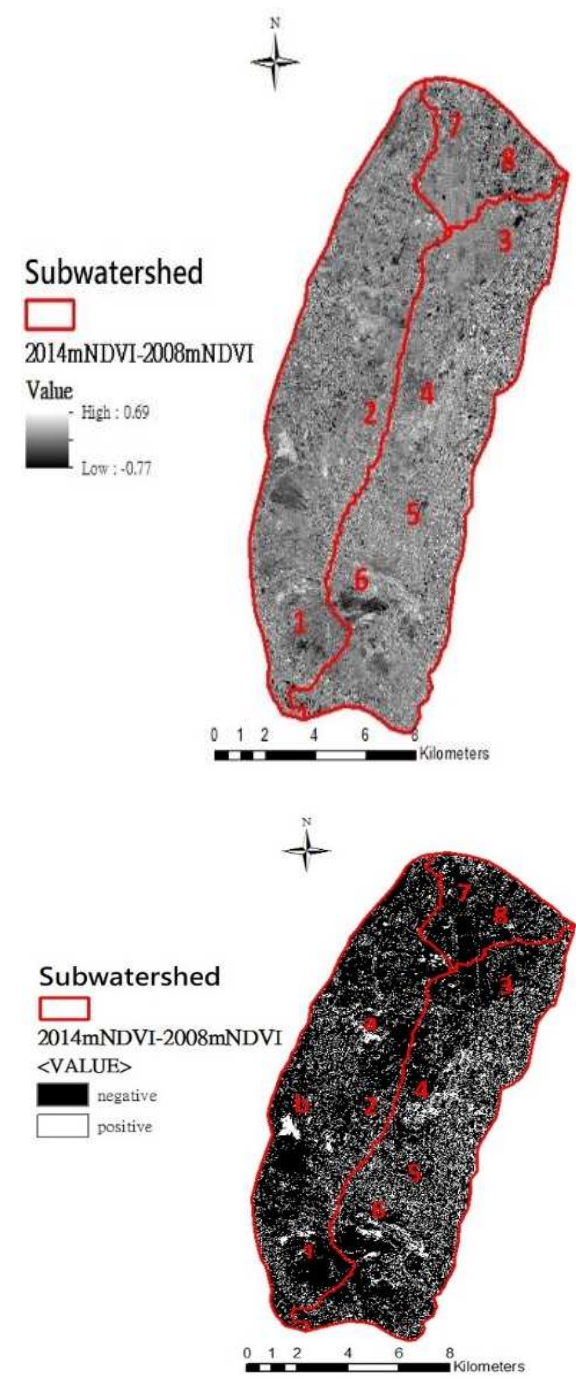

Figure 8. The difference map of $2014 \mathrm{mNDVI}$ and $2008 \mathrm{mNDVI}$ (the upper map is the distribution of 2014 mNDVI minus 2008 mNDVI; the below map is the distribution of negative/positive). 


\subsubsection{Analyzing All Research Area}

As we can see in Table 3, the index of mNDVI in all area cumulate about 26475416 in 2008 and it is about 24452932 in 2014 , it declines $-7.64 \%$. The $\mathrm{mNDVI} / \mathrm{m}^{2}$ for 2008 is 0.63 and 0.58 for 2014, declining -0.05. It reveals that the vegetation coverage is degenerated and represents Chlorophyll content declines, and Oxygen production decreases. It also represents the provision of plant and animal habitat service functions, the first level of productivity, providing human agricultural production function also has reduced.

\subsubsection{Analysis of Sub-Watersheds}

The index of mNDVI for SW-1 cumulate about 12250951 in 2008 and it is about 11441913 in 2014, it's accumulation is the highest in three sub-watersheds, represents the total provision of plant and animal habitat service functions, the total first level of productivity, providing total human agricultural production function is also the highest. But the index declines -809038 from 2008 to 2014 . the $\mathrm{mNDVI} / \mathrm{m}^{2}$ from 2008 to 2014 also changes from 0.63 to 0.58 , declining about -0.04 . It reveals that the vegetation coverage for SW-1 is degenerated and represents Chlorophyll content declines, and Oxygen production decreases. It also represents the provision of plant and animal habitat service functions, the first level of productivity, providing human agricultural production function also has reduced. Compared to other subwatersheds, and the rate of decline is the lowest of three.

The index of mNDVI for SW-2 cumulate about 11395797 in 2008 and it is about 10446426 in 2014 . The index declines -949372 from 2008 to 2014 , and the decline is $-6.60 \%$. The $\mathrm{mNDVI} / \mathrm{m}^{2}$ from 2008 to 2014 also changes from 0.64 to 0.58 , declining about -0.05 . It reveals that the vegetation coverage for SW-2 is degenerated and represents Chlorophyll content declines, and Oxygen production decreases. It also represents the provision of plant and animal habitat service functions, the first level of productivity, providing human agricultural production function also has reduced. Compared to other sub-watersheds, and and the rate of decline is lower than SW-3.

The index of mNDVI for SW-3 cumulate about 2828667 for 2008 and it is about 2564593 for 2014, is lowest of the three. It represents the total provision of plant and animal habitat service functions, the total first level of productivity, providing total human agricultural production function is also the lowest. The index declines -264074 from 2008 to 2014 and the decline is $-9.34 \%$, the highest of the three. The $\mathrm{mNDVI} / \mathrm{m}^{2}$ from 2008 to 2014 also changes from 0.65 to 0.59 , declining about -0.06 . It reveals that the vegetation coverage for SW-3 is degenerated and represents Chlorophyll content declines, and Oxygen production decreases obviously. It also represents the provision of plant and animal habitat service functions, the first level of productivity, providing human agricultural production function also has reduced sharply. Compared to other sub-watersheds, and the rate of decline is highest of the three.

\subsubsection{Hotspot Analysis}

As people can see the left map in Figure 6 (b), there are higher values of the mNDVI in the point 3 (the forest in Qingquan Air Force Base), the point 4 (the forest in Taichung Metropolitan Park), the point 5 (the forest in Donghai University), and the point 6 (the forest in Military area) in $\mathrm{SW}-1$. The four points are darker color in Figure 7 (b). The below of the point 6 in the upper map of Figure 8 reveals the darker color, representing lower values than 2008 because human-induced development. Taichung city government develops The Taichung City Precision Machinery Innovation Technology Park and changes the forest which is belong to Tai Suger farm to human-made buildings. It makes the vegetation coverage in the point 6 is the highest decline point in SW-1. The point 3 , the point 4 , and the point 5 are negative values in the below map of Figure 8, showing the decline of green hotspot is obvious in SW-1 in 2014.

There are higher values of the mNDVI in the point 1 (the forest in the west seep-slope of Datu Tableland), the point 2 (the forest in steep slope of the west) in SW-2 (Figure 6 (b)). The two points are darker color in Figure 7 (b). The point 1 in the upper map of Figure 8 is the darker color, representing lower values than 2008 because of military-induced development. The land cover changes from the forest to military building. There are many dark and bright pixels mixed in the point 2 because many human buildings are established along the Taiwan street. many dryfarms are changed to new buildings. The vegetation coverage in the point 1 is the black area in the below map of Figure 8, representing that the vegetation coverage is decreased. The point 3 , the point 4 , and the point 5 are negative values in the below map of Figure 8, showing the decline of green hotspot is obvious in SW-1 in 2014. The below of the point a in the below map of Figure 8 reveals the positive value, representing higher vegetation coverage than 2008 because of good ecological conservation of the forest in Providence University. The point $b$ in the below map of Figure 8 is also the positive value, representing higher vegetation coverage than 2008 because of new grass cover which replaces the wasteland wildfire-happened in 2008.

There are higher values of the mNDVI in the point 7 (the grassland in the northern Golf \& Country Club of Qingquan Air Force Base), the point 8 (the fruit trees in the north) in SW-3 (Figure 6 (b)). The two points are darker color in Figure 7 (b). The point 7 in the upper map of Figure 8 is the darker color, representing lower values. The land cover of the point 7 is the same from 2008 to 2014 . There are more dark pixels mixed in the point 8 because many human buildings (factories) are established. Many areas of fruit trees (eg: Litchi chinensis) are changed to new buildings (most of them are factories). The vegetation coverage in the point 8 is the black area in the below map of Figure 8, representing that the vegetation coverage is decreased. The point 7 and the point 8 are negative values in the below map of Figure 8 , showing the decline of green hotspot is obvious in SW-3 in 2014. These two hotspots need to be conserved. 
Table 3. The information of mNDVI of 2014 and $m$ NDVI of 2008.

\begin{tabular}{llllll}
\hline & year & SW-1 & SW-2 & SW-3 & All area \\
\hline \multirow{3}{*}{ Sum of mNDVI } & 2008 & 12250951 & 11395797 & 2828667 & 26475416 \\
& 2014 & 11441913 & 10446426 & 2564593 & 24452932 \\
\multirow{2}{*}{ Decline (\%) } & 2014 minus 2008 & -809038 & -949372 & -264074 & -2022483 \\
& & $-6.60 \%$ & $-8.33 \%$ & $-9.34 \%$ & $-7.64 \%$ \\
mNDVI/m & 2008 & 0.63 & 0.64 & 0.65 & 0.63 \\
& 2014 & 0.58 & 0.58 & 0.59 & 0.58 \\
& 2014 minus 2008 & -0.04 & -0.05 & -0.06 & -0.05 \\
\hline
\end{tabular}

\subsection{Analysis of the Water Storage Capacity}

This study use the potential maximum retention amount (S) as index of assessing water conservation, reducing soil erosion, and water purification. The step is to calculate the spatial distribution of maximum retention amount (Figure 12 (a)) and the spatial distribution of the curve number (Figure 11 (a)) for 2008 by Curve number of SCS (Table 2) according to the spatial distribution of landscapes for 2008 (Figure 9 (a)) and the spatial distribution of soil category (Figure 10). It can be done to calculate the spatial distribution of maximum retention amount (Figure 12 (b)) and the spatial distribution of the curve number (Figure 11 (b)) for 2014 by Curve number of SCS (Table 2) according to the spatial distribution of landscapes for 2014 (Figure 9 (b)) and the spatial distribution of soil category (Figure 10). The information of the maximum retention amount for 2014 and 2008 in the research area and sub-watersheds can be seen in Table 4.

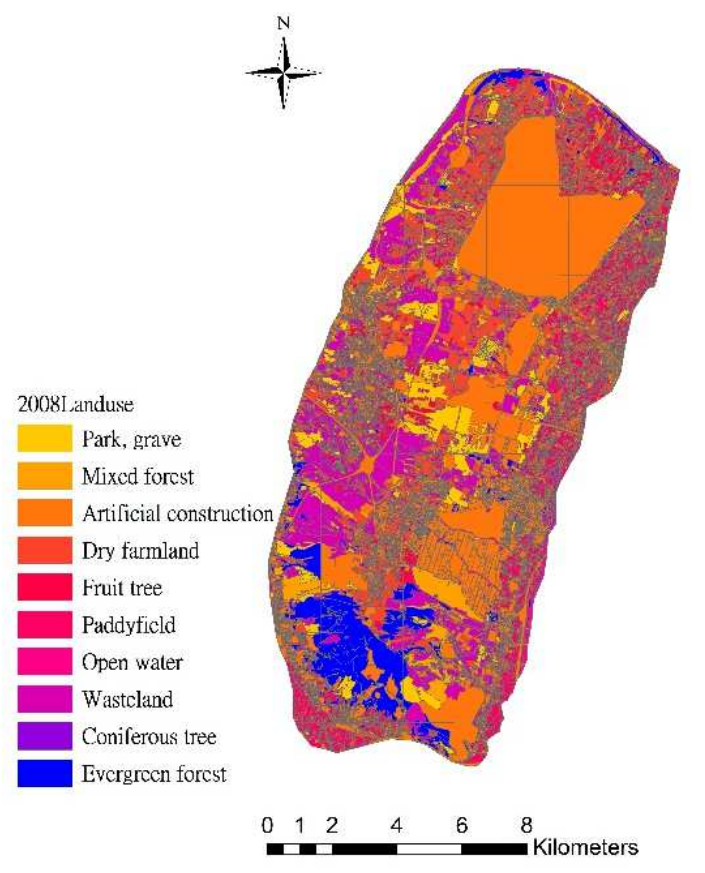

(a) 2008

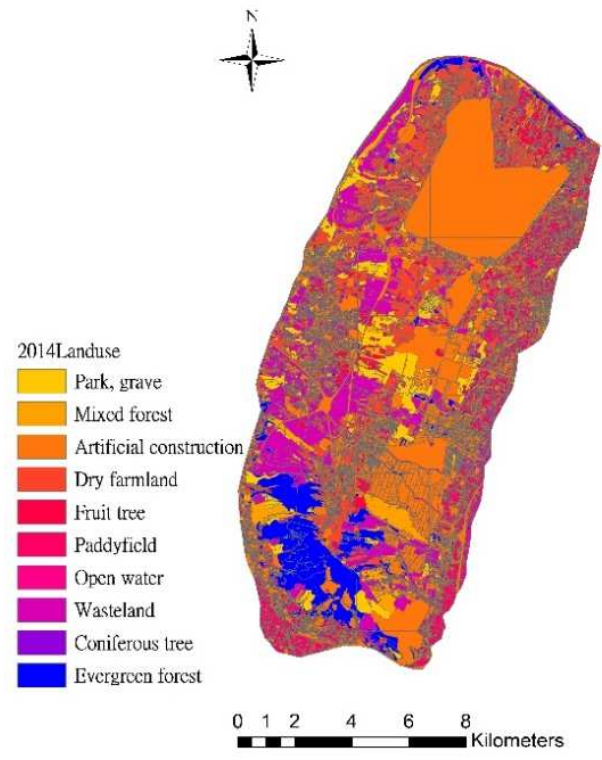

(b) 2014

Figure 9. Spatial distribution of landscapes for 2008 and 2014.

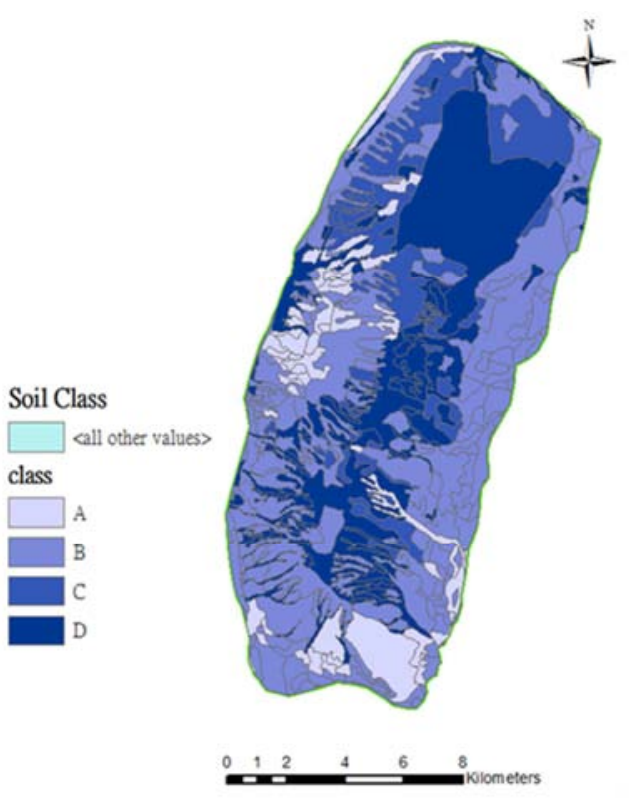

Figure 10. Spatial distribution of soil category. 


\subsubsection{Analyzing All Research Area}

As people can see in Table 4, the index of $\mathrm{S}$ in all area cumulate about $11941431018 \mathrm{~mm}$ in 2008 and it is about $11868353065 \mathrm{~mm}$ in 2014 , it declines $-73077953 \mathrm{~mm}$ totally and the rate is $-0.61 \%$. The $\mathrm{S} / \mathrm{m} 2$ for 2008 is $71.29 \mathrm{~mm} / \mathrm{m}^{2}$ and the $\mathrm{S} / \mathrm{m}^{2}$ for 2014 is $70.85 \mathrm{~mm} / \mathrm{m}^{2}$, declining -0.44 $\mathrm{mm} / \mathrm{m}^{2}$. It reveals that the water storage capacity is degenerated and represents the ability of retaining and infiltrating water declines, and the function of purification decreases. It also represents the provision of the water to plant and animal habitat also has reduced.

\subsubsection{Analysis of Sub-Watersheds}

The index of S for SW-1 cumulate about $5093877219 \mathrm{~mm}$ for 2008 and it is about $5075372874 \mathrm{~mm}$ for 2014, it's accumulation is the second high in three sub-watersheds, represents the total ability of retaining and infiltrating water declines, and the total function of purification is the second of all. But the index declines $-18504345 \mathrm{~mm}$ from 2008 to 2014 , and declining rate is about $-0.36 \%$. the $\mathrm{S} / \mathrm{m}^{2}$ from 2008 to 2014 also changes from $65.02 \mathrm{~mm} / \mathrm{m}^{2}$ to $64.77 \mathrm{~mm} / \mathrm{m}^{2}$, declining about $-0.25 \mathrm{~mm} / \mathrm{m}^{2}$. It reveals that he maximum retention amount for SW-1 for 2014 is degenerated and represents the ability of retaining and infiltrating water declines, and the function of purification decreases compared to that for 2008. It also represents the provision of plant and animal habitat service functions, the first level of productivity, providing water for human agricultural production function also has reduced. Compared to other sub-watersheds, the rate of decline is the lowest of three.

The index of S for SW-2 cumulates about $5811781447 \mathrm{~mm}$ for 2008 and it is about $5778385296 \mathrm{~mm}$ for 2014 , and the accumulation is the highest in three sub-watersheds, represents the total ability of retaining and infiltrating water declines, and the total function of purification is the highest of all. But the index declines $-33396151 \mathrm{~mm}$ from 2008 to 2014 , and the rate of decline is about $-0.57 \%$. the $\mathrm{S} / \mathrm{m}^{2}$ from 2008 to 2014 also changes from $81 \mathrm{~mm} / \mathrm{m}^{2}$ to $80.53 \mathrm{~mm} / \mathrm{m}^{2}$, declining about $-0.47 \mathrm{~mm} / \mathrm{m}^{2}$. It reveals that he maximum retention amount for SW-2 for 2014 is degenerated and represents the ability of retaining and infiltrating water declines, and the function of purification decreases compared to that for 2008. It also represents the provision of plant and animal habitat service functions, the first level of productivity, providing water for human agricultural production function also has reduced. Compared to other sub-watersheds, the rate of decline is next to the lowest value of three.

The index of S for SW-3 cumulates about $1035772352 \mathrm{~mm}$ for 2008 and it is about $1014594896 \mathrm{~mm}$ for 2014, it's accumulation is the lowest in three sub-watersheds, represents the total ability of retaining and infiltrating water declines, and the total function of purification is the lowest of all. But the index declines $-21177456 \mathrm{~mm}$ from 2008 to 2014, and the rate of decline is about $-2.04 \%$. The rate of decline is the highest of three. The $\mathrm{S} / \mathrm{m}^{2}$ from 2008 to 2014 also changes from $59.49 \mathrm{~mm} / \mathrm{m}^{2}$ to $58.27 \mathrm{~mm} / \mathrm{m}^{2}$, declining about
$-1.22 \mathrm{~mm} / \mathrm{m}^{2}$. The rate of decline for The $\mathrm{S} / \mathrm{m}^{2}$ is the highest of three. It reveals that he maximum retention amount for SW-3 for 2014 is degenerated obviously and represents the ability of retaining and infiltrating water for per square meter declines, and the function of purification for per square meter decreases compared to that for 2008. It also represents the provision of plant and animal habitat service functions, the first level of productivity, providing water for human agricultural production function also has reduced obviously. Compared to other sub-watersheds, the rate of decline is the lowest value of three.

\subsubsection{Hotspot Analysis}

There are higher values of the maximum retention amount in the point 1 (the forest in the west of military base) and the point 2 (the evergreen forest) in SW-1 seen in Figure 12 (a). The two points seem the same values in Figure 12 (b). The position of the point a in Figure 13 reveals the deep blue color, representing higher values than 2008 because the mixed reforest. The below of the point $b$ in Figure 13 (a) reveals the higher blue color, representing higher values than 2008 because human-induced development. Taichung city government develops The Taichung City Precision Machinery Innovation Technology Park and changes the wasteland in 2008 to be the factories in 2014. It makes the water capacity in the point $b$ is the higher increasing point in SW-1 and the red color, representing positive values. It means the part of the point $b$ has good capacity for water capacity. There are some orange color pixels (it means lower values than 2008) in the point $b$ in Figure 13 (a) and negative values in Figure 13 (b), representing lower values than 2008 because human-induced development. Taichung city government develops The Taichung City Precision Machinery Innovation Technology Park and changes the evergreen forest in 2008 to be the wasteland in 2014. The below of the point $\mathrm{c}$ in Figure 13 (a) reveals the higher blue color, representing higher values than 2008 because humaninduced development. Taiwan government developed The Central Taiwan Science Park and changes the wasteland in 2008 to be the factories in 2014 . It makes the water capacity in the point $\mathrm{c}$ is the higher increasing point in SW-1 and the red color, representing positive values. It means the part of the point $\mathrm{c}$ has good capacity for water capacity. There are some orange/red color pixels (it means lower values than 2008) in the point $\mathrm{c}$ in Figure 13 (a) and negative values in Figure 13 (b), representing lower values than 2008 because human-induced development. Some landscapes are changed from the grave/park in 2008 to the wastelands which is to be factories in 2014.

There are higher values of the maximum retention amount in the point 3 (the evergreen forest in the southern west steep slope) and the point 4 (Taichung Metropolitan Park) in SW-2 seen in Figure 12 (a). The two points seem the same values in Figure 12 (b). These points are the hotspots for water capacity because of their big areas in SW-2. The upper position of the point $d$ in Figure 13 (a) reveals the deep blue color, representing higher values than 2008 because the 
evergreen reforest. Military government developed the military buildings and changes the wasteland in 2008 to be the evergreen forest in 2014. It makes the water capacity in the upper position of the point $d$ is the higher increasing point in SW-2 and the red color in Figure 13 (b) represents positive values. It means the upper position of the point $b$ has good capacity for water capacity. There are some red color pixels (it means lower values than 2008) in the below position of the point $d$ in Figure 13 (a) and negative values in Figure 13 (b), representing lower values than 2008 because of humaninduced development. Air Defense Missile Base builded the new military buildings and changes the evergreen forest in 2008 to be the wasteland in 2014 . It means the water capacity in the below position of the point $d$ is the higher decreasing point in SW-2 and the green color in Figure 13 (b) represents negative values. The below position of the point $b$ has bad capacity for water capacity. The position of the point $g$ in Figure 13 (a) reveals the bright blue color, representing higher values than 2008 because human-induced development. The new houses in 2014 replace the wasteland in 2008. It makes the water capacity in the point $g$ is the higher increasing point in SW-2 and the red color, representing positive values. It means the part of the point $g$ has good capacity for water capacity. There are some blue color pixels and orange/red color pixels mixed in the point $\mathrm{e}$ in Figure 13 (a). These few blue pixels (positive values) enrich the maximum retention amount because the landscapes change from the wasteland in 2008 to the buildings in 2014. A lot of orange/red color pixels (negative values) reveal the maximum retention amount decreased because the landscapes change from the park/grave and dryland in 2008 to the buildings in 2014. The same situation happens in the point $f$ in Figure 13 (a). These few blue pixels (positive values) in the point of enrich the maximum retention amount because the landscapes change from the wasteland in 2008 to the buildings or drylands in 2014. A lot of orange/red color pixels (negative values) reveal the maximum retention amount decreased because the landscapes change from the drylands or the fruit trees in 2008 to the buildings or drylands in 2014.

There are higher values of the maximum retention amount in the point 5 (the fruit forests) and the point 6 (the evergreen forest in the north steep slope) in SW-3 seen in Figure 12 (a). The point 5 has more orange/red pixels in Figure 12 (b) and the several yellow patches are Fragmented and destructed and their patches shows the emergence of discontinuities. The position of the point $h$ in Figure 13 (a) reveals the orange/red color pixels, representing negative values. Some landscapes change from the fields in 2008 to be the artificial buildings in 2014, and others change from the fruit trees to fields. These changes make the maximum retention amount decreased, representing lower values than 2008 because human-induced development. The distribution shows green color/negative values in Figure 13 (b).

Table 4. The information of the maximum retention amount for 2014 and 2008.

\begin{tabular}{|c|c|c|c|c|c|}
\hline & year & SW-1 & SW-2 & SW-3 & All area \\
\hline \multirow{3}{*}{ sum of $\mathrm{S}(\mathrm{mm})$} & 2008 & 5093877219 & 5811781447 & 1035772352 & 11941431018 \\
\hline & 2014 & 5075372874 & 5778385296 & 1014594896 & 11868353065 \\
\hline & 2014 minus 2008 & -18504345 & -33396151 & -21177456 & -73077953 \\
\hline Decline $(\%)$ & 2008 & 65.02 & 81 & 59.49 & 71.29 \\
\hline \multirow[t]{2}{*}{$\mathrm{S} / \mathrm{m}^{2}$} & 2014 & 64.77 & 80.53 & 58.27 & 70.85 \\
\hline & 2014 minus 2008 & -0.25 & -0.47 & -1.22 & -0.44 \\
\hline
\end{tabular}

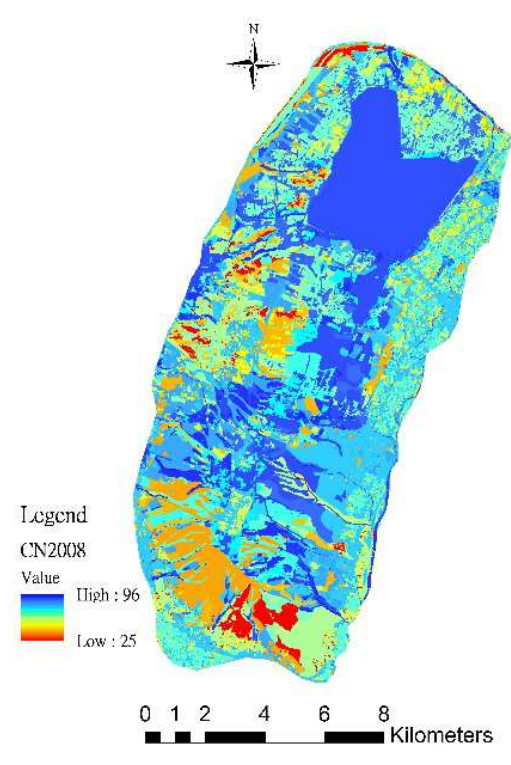

(a) 2008

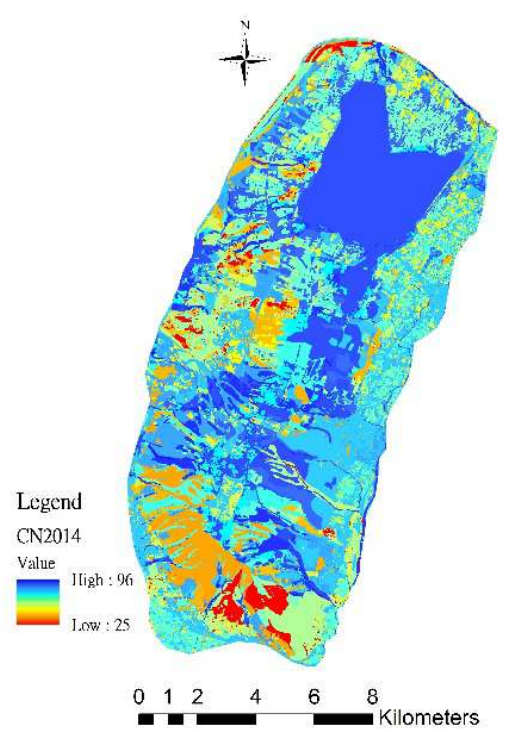

(b) 2014

Figure 11. The distribution of the curve number for 2008 and 2014. 


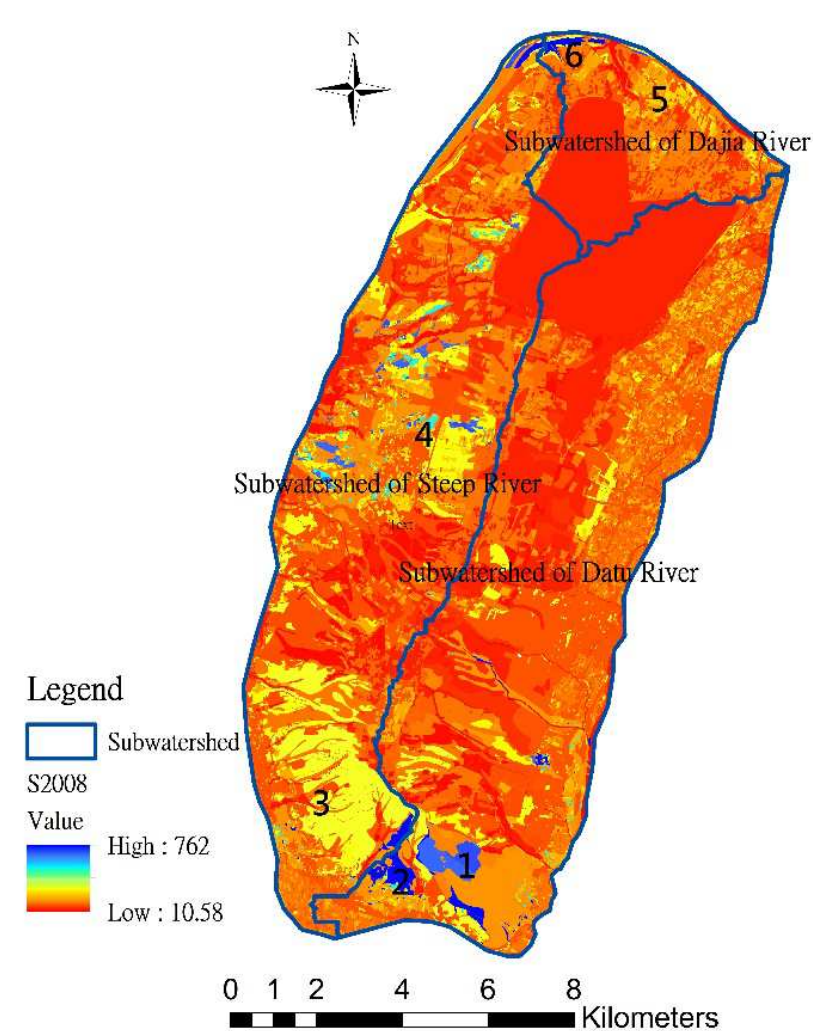

(a) 2008

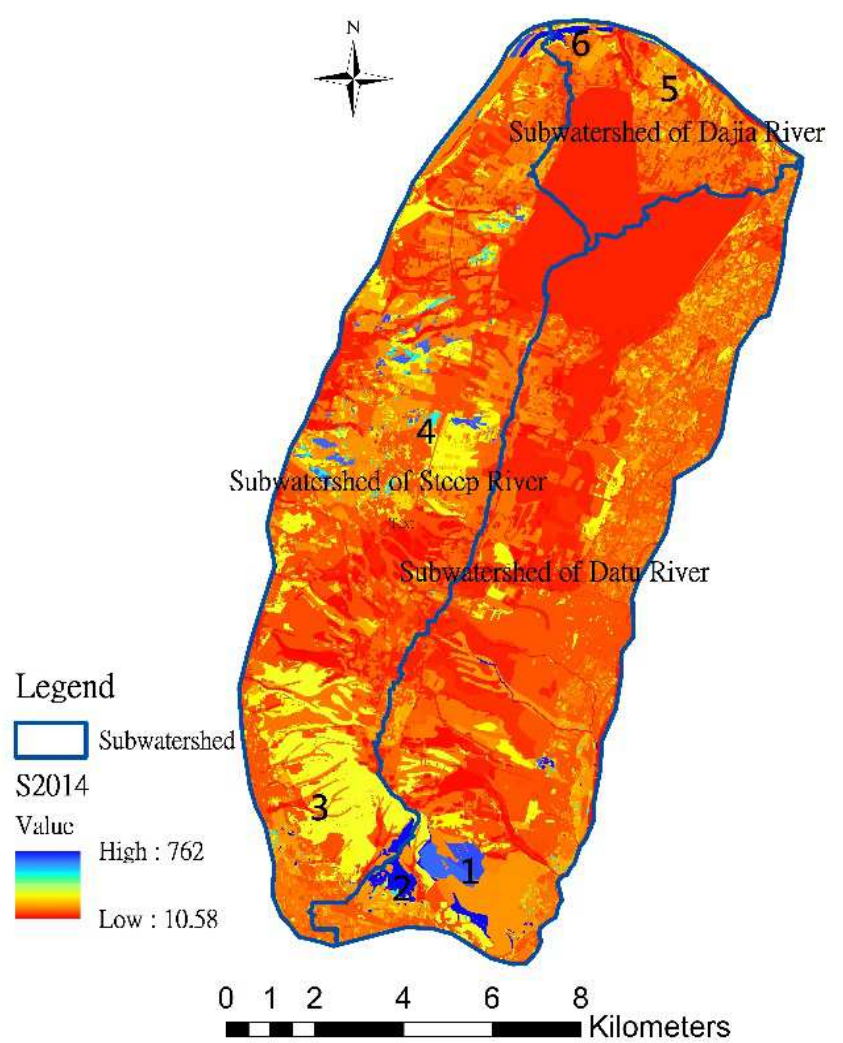

(b) 2014

Figure 12. The distribution of the maximum retention amount for 2008 and 2014.

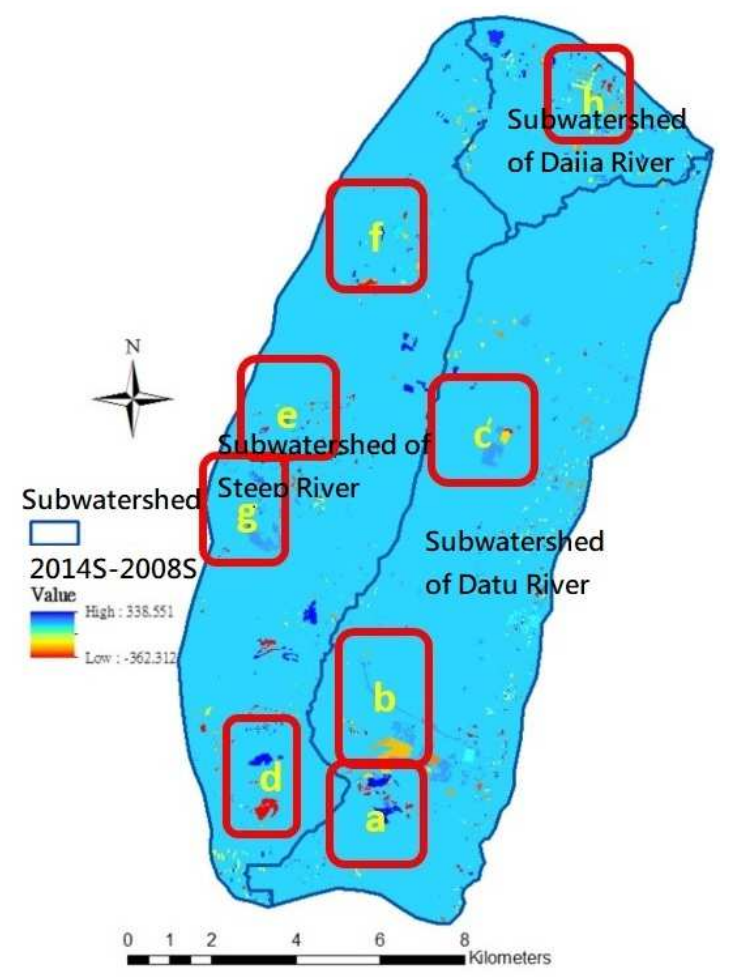

(a)

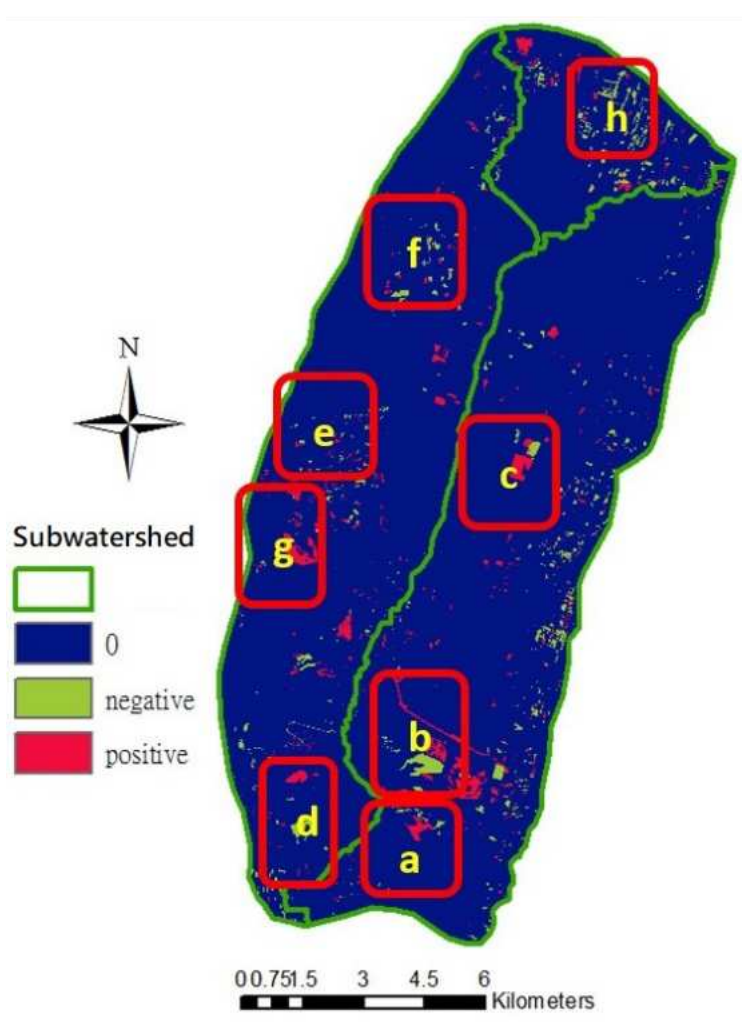

(b)

Figure 13. The distribution map of 2014 S minus 2008 S (a) and the hotspot of the distribution of negative/positive values (b).

\section{Summary and Conclusions}

The main LULC changes in this geomorphologic region 
from 2000 to 2015 were the transformation of dry farmland into built-up land, or evergreen forests/fruit forests into dry farmland and built-up land. This study calculate the spatial distribution of vegetation coverage and water capacity and show how much built-up land contribute to water yield. At geomorphologic region scale, the estimation of the simulated hydrological index of two LULC maps can be shown. In subwatersheds of morphologic region, obvious LULC changes to the response of hydrological index and mNDVI can be estimated and this study can also calculate how much built-up land can be built-up and it increases the risk of flood because of decreasing the landscape which have the abilities to capacity water. The easy and distinct approach of quantifying the impacts of landscape changes on hydrology and ecological services at different scales including geomorphic and hydrological scales provides quantitative information for stakeholders in making decisions for land and water resource management by linking a hydrological model and a ecological service model to remote sensing image analysis.

\section{References}

[1] Helmschrot J, Flugel WA. (2002). Land use characterisation and change detection analysis for hydrological model parameterisation of large scale afforested areas using remote sensing. Physics and Chemistry of the Earth, 27 (9-10): 711718 .

[2] Yang, K. C. (2010). Investigation, the survey data, and distributed information of the growing condition of surveying plant and the growing condition of all individuals in Taichung Metropolitan Park. Construction and Planning Agency, Ministry of the Interior. http://www.cpami.gov.tw/filesys/file/chinese/publication/plan/ 99122099.pdf. (accessed 2017/05/20).

[3] Sellers, P. J. (1985). Canopy reflectance, photosynthesis and transpiration. International Journal of Remote Sensing, 6 (8), 1335-72.

[4] Nathalie Pettorelli, Jon Olav Vik, Atle Mysterud, Jean-Michel Gaillard, Compton J. Tucker and Nils Chr. Stenseth. (2005). Using the satellite-derived NDVI to assess ecological responses to environmental change. TRENDS in Ecology and Evolution 20 (9): 503-510.

[5] Senay, G. B., Verdin, J. P. (2004). Developing index maps of water-harvest potential in Africa. Appl Eng Agric 20 (6): 789799 .

[6] Shereif H. Mahmoud, A. A. Alazba. (2015). Hydrological Response to Land Cover Changes and Human Activities in Arid Regions Using a Geographic Information System and Remote Sensing. PLoS One Published online 2015 Apr 29, 10 (4): e0125805.

[7] Lin, Y. P., Wu, C. F., Teng, T. P. (2004). Apply Landscape Ecological Matrics to Characterize Spatiotemporal Land Use Mosaic in Hsichih area from 1990 to 2001 . Journal of City and Planning, 31 (3): 239-268.

[8] Yang, P. R. (2001). Landscape Ecology in City Planning: Urban Development, Landscape Change and Hydrological Effect in Taipei's Keelung River Basin 1980-2000. Doctor's
Thesis, Graduate Institute of Building and Planning, National Taiwan University.

[9] Hernandez-Guzman R, Ruiz-Luna A, Berlanga-Robles C. A. (2008). Assessment of runoff response to landscape changes in the San Pedro subbasin (Nayarit, Mexico) using remote sensing data and GIS. Journal of environmental science and health. Part A, Toxic/hazardous substances \& environmental engineering, 43 (12): 1471-1482.

[10] Savary, S., Rousseau, A. N., Quilbe, R. (2009). Assessing the effects of historical land cover changes on runoff and low flows using remote sensing and hydrological modeling. Journal of Hydrologic Engineering, 14 (6): 575-587.

[11] Baldyga, T. J., Miller, S. N., Driese, K. L., Gichaba, C. M. (2008). Assessing land cover change in Kenya's Mau Forest region using remotely sensed data. African Journal of Ecology, 46 (1): 46-54.

[12] Enrique, M. T., Javier, Z., Kazi, R., Ana, G. S., J. Ignacio, L. M., Sergio, V. S., A. L. Christina, L. Tague and Martin, B. (2014). Hydrological impacts of climate and land-use changes in a mountain watershed: uncertainty estimation based on model comparison. Ecohydrology. Published online in Wiley Online Library (wileyonlinelibrary.com) DOI: 10.1002/eco.1590.

[13] Sharma, T., Satya Kiran, P. V., Singh, T. P., Trivedi, A. V., Navalgund, R. R. (2001). Hydrologic response of a watershed to land use changes: A remote sensing and GIS approach. International Journal of Remote Sensing, 22 (11): 2095-2108.

[14] Kepner, W., Hernandez, M., Semmens, D., Goodrich, D. (2008). The Use of Scenario Analysis to Assess Future Landscape Change on a Watershed Condition in the Pacific Northwest (USA). Use of Landscape Sciences for the Assessment of Environmental Security. The Netherlands: Springer, ISBN 978-1--4020-6588-0. pp. 237-261.

[15] Chung, Y. L. (2005). Using SPOT Satellite Imagery to Monitor the Forest Dynamic at Landscape Level, Journal of Photogrammetry and Remote Sensing. Volume 10, 4, December 2005, pp. 315-326.

[16] Tucker C. J. \& Sellers, P. J. (1986). Satellite remote sensing of primary production. International Journal of Remote Sensing, 7 (11), 1395-416.

[17] Pang, Y. H. (2013). Analysis of the Ecological Quality and Habitat Fragmentation on the Toucian River Basin. Journal of Environment and Management, 13 (2): 1-17.

[18] Lin, C. Y., Tseng, H. F., Fu, K. L. (2016). Assessment of Flood and Sediment Disaster Potential Area on Datu Terrace. Journal of Soil and Water Conservation, 48 (3): 1803-1816.

[19] Chu, C. M., Lin, C. Y. (2016). Discussion of detention facility with different land development type, Journal of Soil and Water Conservation, 48 (3): 1817-1830.

[20] Hsu, H. H., Kao, C. L. (2007). A study of Technical Handbook for Soil Water Content of Green Buildings in Taiwan. Architecture and building research institute, ministry of the interior research project report.

[21] Tsai, H., Hseu, Z. Y., Huang, S. T., Huang, W. S., Chen, Z. S. (2009). Pedogenic properties of surface deposits used as evidence for the type of landform formation of the Tadu tableland in central Taiwan, Geomorphology, 114 (4): 590600 . 